University of Nebraska - Lincoln

DigitalCommons@University of Nebraska - Lincoln

Faculty Publications, Department of Psychology

Psychology, Department of

June 2000

\title{
Parental Monitoring and Adolescent Adjustment: An Ecological Perspective
}

Kristen C. Jacobson

Virginia Commonwealth University

Lisa J. Crockett

University of Nebraska-Lincoln, ecrockett1@unl.edu

Follow this and additional works at: https://digitalcommons.unl.edu/psychfacpub

Part of the Psychiatry and Psychology Commons

Jacobson, Kristen C. and Crockett, Lisa J., "Parental Monitoring and Adolescent Adjustment: An Ecological Perspective" (2000). Faculty Publications, Department of Psychology. 231.

https://digitalcommons.unl.edu/psychfacpub/231

This Article is brought to you for free and open access by the Psychology, Department of at DigitalCommons@University of Nebraska - Lincoln. It has been accepted for inclusion in Faculty Publications, Department of Psychology by an authorized administrator of DigitalCommons@University of Nebraska - Lincoln. 


\title{
Parental Monitoring and Adolescent Adjustment: An Ecological Perspective
}

\author{
Kristen C. Jacobson \\ Virginia Institute for Psychiatric and Behavioral Genetics \\ Virginia Commonwealth University \\ Lisa J. Crockett \\ Department of Psychology \\ University of Nebraska at Lincoln
}

This study uses an ecological framework to examine the associations between parental monitoring and a variety of indicators of adolescent adjustment. Specifically, investigators examined whether higher levels of parental monitoring were associated with higher adolescent grade point average, lower levels of adolescent depression, and lower levels of adolescent sexual activity and minor delinquency, and whether these relations were moderated by gender, grade level, or mothers' work status. Participants were 424 7th to 12th graders from a single rural school district in central Pennsylvania. Bivariate correlations indicated that parental monitoring had strong associations with all indicators of adjustment for both boys and girls, with the exception of boys' depression. Gender and grade level simultaneously moderated the relation between parental monitoring and adolescent delinquency, with the effect of parental monitoring increasing across grade level for boys, and decreasing with grade level for girls. Furthermore, maternal employment moderated the relation between monitoring and adolescent delinquency and sexual behavior. For both boys and girls, monitoring was a significant predictor of problem behaviors among adolescents whose mothers worked full time. Thus, effective monitoring may compensate for a lack of direct supervision. However, gender further moder-

Requests for reprints should be sent to Kristen C. Jacobson, Virginia Institute for Psychiatric and Behavioral Genetics, Virginia Commonwealth University, 800 East Leigh Street, P.O. Box 980126, Richmond, VA 23298-0126. Email: jacobson@physio.vipbg.vcu.edu 
ated these associations. Specifically, the relation between monitoring and adjustment was also significant among girls when their mothers were not working and among boys when mothers worked at least part time.

In recent years there has been increasing interest in the processes through which parents facilitate the adjustment of their adolescent children. One such process is parental monitoring, which is generally defined as the parents' knowledge of their child's whereabouts, activities, and friends. Empirical research has supported the association between parental monitoring and a variety of adjustment indicators. For example, higher levels of parental monitoring have been associated with lower levels of antisocial behavior (e.g., Patterson \& Stouthamer-Loeber, 1984; Snyder, Dishion, \& Patterson, 1986), substance use (e.g., Brown, Mounts, Lamborn, \& Steinberg, 1993; Dishion \& Loeber, 1985), and sexual behavior (e.g., Crockett \& Bingham, 1994; Hogan \& Kitagawa, 1985), and with better school functioning (e.g., Brown etal.,1993; Dornbusch, Ritter, Leiderman, Roberts, \& Fraleigh, 1987).

Although such studies point to the importance of parental monitoring for child and adolescent adjustment, an ecological perspective (e.g., Bronfenbrenner, 1979) cautions against drawing hasty conclusions regarding the global importance of this dimension of parenting. Because family processes always occur within a specific family context, and each individual brings to the family certain personal attributes and characteristics, family processes may have different effects for different groups of individuals in distinct family settings. For example, Steinberg, Mounts, Lamborn, and Dornbusch (1991) reported that although the associations between parenting style and adolescent adjustment appear to transcend socioeconomic class and family structure, they are stronger for White and Hispanic American adolescents than for African or Asian American adolescents. These results suggest that certain aspects of parenting style work better in some ecological niches than in others. Similarly, an ecological perspective suggests that adolescents with different personal characteristics (e.g., gender and age) or those in different family contexts (e.g., dual-earner vs. single-earner families) may be differentially affected by parental monitoring. The purpose of this study is to examine the differential importance of parental monitoring for adolescents in distinct subgroups defined by gender, age, and maternal employment.

\section{PARENTAL MONITORING AND ADOLESCENT ADJUSTMENT}

Prior research indicates a relation between parental monitoring and several aspects of adolescent adjustment. For example, Patterson and 
Stouthamer-Loeber (1984) and Snyder et al. (1986) reported that rates of delinquency in their samples of 4th-, 7th-, and 10th-grade boys were significantly and negatively correlated with parental monitoring. Additionally, levels of parental monitoring were found to differentiate between moderate and chronic offenders (Patterson \& Stouthamer-Loeber, 1984). Similarly, in their reanalysis of Glueck and Glueck's data from the Great Depression, Sampson and Laub (1994) reported strong associations between parental monitoring and delinquency, with higher monitoring associated with lower delinquency.

Levels of parental monitoring and related parenting practices have also been linked to sexual behavior. Hogan and Kitagawa (1985) found that parental supervision of dating was negatively correlated with sexual activity in a sample of urban, African American girls. In a similar vein, Ensminger (1990) found that African American girls who were sexually active were more likely to have permissive parental rules about curfews than girls who were not sexually active. Similar associations between parental monitoring and adolescent sexual behavior have also been found for White female adolescents (Crockett \& Bingham, 1994).

Parental monitoring has been linked to adolescents' school functioning as well (e.g., Dornbusch et al., 1987). For example, Crouter, MacDermid, McHale, and Perry-Jenkins (1990) found that lower levels of parental monitoring were associated with lowered rates of school competence among fourth- and fifth-grade boys. Additionally, Brown et al. (1993) reported that levels of parental monitoring were positively correlated with adolescent grade point average (GPA).

Finally, some research indicates that parental monitoring is associated with adolescents' emotional well-being. Barber, Olsen, and Shagle (1994) found that lack of behavioral control by parents was related to adolescent internalizing problems, although it was more strongly related to adolescent externalizing problems. On the other hand, using a small sample of eighth graders, Linver and Silverberg (1995) reported that parental monitoring did not account for any additional variance in self-esteem and psychological symptoms when entered into a hierarchical regression after parental respect for their adolescents or parental psychological control. In contrast, parental monitoring did explain a significant amount of variance in problem behavior when entered in after parental respect or psychological control. These studies suggest that parental monitoring may be less important for variation in adolescent depressed mood than for variation in adolescent social and achievement-related behaviors. 


\title{
PARENTAL MONITORING IN AN ECOLOGICAL FRAMEWORK
}

\begin{abstract}
Although findings from the current literature on family processes suggest that there is a strong association between parental monitoring and adolescent adjustment, few studies have examined these associations from an ecological perspective. Such a framework suggests that the effects of family processes may differ for youth with distinct person and context characteristics (Bronfenbrenner, 1986, 1988). In line with this perspective, results from several ecologically oriented studies illustrate that parental monitoring may not have identical effects for adolescents of differing gender, age, and maternal employment status.
\end{abstract}

\section{Gender Differences}

Although only a few studies have compared the impact of monitoring and supervision for boys versus girls, several that have done so suggest that parental monitoring could have a stronger association with behavioral adjustment for girls than for boys. Steinberg (1986) found that fifth- through eighth-grade girls who were on their own after school were more susceptible to peer pressure than girls who were in adult-supervised environments. Among boys, this difference was not significant. Similarly, Galambos and Maggs (1991) reported that sixth-grade girls who were most removed from adult supervision reported more problem behavior and more contact with deviant peers than girls who were more closely supervised, whereas the associations between adult supervision and outcomes were not as strong for boys. On the other hand, Weintraub and Gold (1991) found a significant gender by monitoring interaction for adolescent delinquency in a sample of 11- to 18-year-olds, where parental monitoring was more strongly associated with delinquency among boys than among girls.

In contrast, there is some evidence that parental monitoring may have a stronger association with academic achievement for boys than for girls. Crouter et al. (1990) reported a significant gender by monitoring interaction for GPA in their sample of fourth and fifth graders. Follow-up tests revealed that poorly monitored boys had lower grades than did well-monitored boys or girls (regardless of level of parental monitoring). Girls, however, showed no differences in grades due to level of parental monitoring.

These findings indicate that models of family processes should include gender, to determine whether the associations between family processes and adjustment are uniform across gender. They also suggest that any dif- 
ferential importance of parental monitoring for boys relative to girls may depend on the type of outcome variable assessed.

\section{Grade Level Differences}

As with gender, only a few studies have compared the impact of parental monitoring for adolescents of different ages. Instead, researchers commonly focus on a single age group (e.g., Ensminger, 1990), combine different ages into one analysis (e.g., Dishion \& Loeber, 1985; Patterson \& Stouthamer-Loeber, 1984), or control for the effects of age statistically (e.g., Brown et al., 1993; Steinberg, Elmen, \& Mounts, 1989). Some research, however, indicates that family processes may not have the same effects on adjustment at all ages. For example, Snyder et al. (1986) found that poor parental monitoring was significantly correlated with association with deviant peers for 7 th- and 10 th-grade boys, but not for 4 th-grade boys. Additionally, Foxcraft (1994) reported that perceived parental control was negatively associated with drinking behavior in adolescents aged 15 to 16 , but not for those aged 11 to 12 . These studies suggest that parental monitoring may become increasingly important as adolescents enter high school.

However, there is also evidence that the effects of parental monitoring may also decrease during the later high school years. For example, Weintraub and Gold (1991) tested a curvilinear effect of parental monitoring on delinquency in the National Survey of Youth (Gold \& Reimer, 1975) by creating a dummy variable for age that assigned both 11- and 12-year-olds and 17- to 18-year-olds a score of 0 , and 13- to 16-year-olds a score of 1 . The interaction between parental monitoring and the dummy variable was significant, indicating that parental monitoring had a greater association with delinquency for 13- to 16-year-olds than either older or younger adolescents. Finally, Small (1995) reported that although poor parental monitoring was associated with adolescent binge drinking in general, the associations were stronger in 9th grade than in either 7th or 11th grade.

Although the empirical evidence regarding the influence of age on the associations between parental monitoring and adolescent adjustment is both limited and somewhat inconsistent, there are conceptual reasons to believe that age (and grade level) might moderate the association between parental monitoring and adolescent adjustment. To begin with, it is generally accepted that adolescence is a period of increasing autonomy (e.g., Steinberg, 1990). Likewise, older adolescents spend less time with family and more time with friends than preadolescents and younger adolescents (Larson \& Richards, 1991). Thus, opportunities for direct parental supervision are more limited as adolescents age. Furthermore, peer influences become 
stronger, particularly during early to midadolescence (Berndt, 1979; Brown, 1990), and participation in some deviant behaviors, such as delinquency and drug use, is highest during midadolescence (Menard \& Elliott, 1990). Therefore, it can be reasoned that as direct supervision decreases, and opportunity and motivation to participate in deviant behavior increases, the distal effects of parental monitoring may become a more important factor for adolescent adjustment. Thus, the effectiveness of parental monitoring may increase, in general, across the adolescent years, and might be particularly important during the early high school years (i.e., Grades 9 and 10) when direct parental supervision has declined, peer influence is at its peak, and opportunities for deviant behavior are increasing.

\section{Mothers' Work Status}

Just as person characteristics may moderate the relation between parental monitoring and adjustment, the family context of the adolescent may also moderate this relation. Bronfenbrenner and Crouter (1983) highlighted several family context variables that comprise the "new demography." One important aspect of family context is maternal employment. It is possible that in families in which the mother works full time, and is thus not physically present for the adolescent, effective parental monitoring may be more important in preventing negative outcomes than in families in which the mother does not work full time. Although much research has been done on the general effects of maternal employment on child and adolescent adjustment (e.g., Armistead, Wierson, \& Forehand, 1990), there has been less attention paid to how maternal employment may moderate the relations between family processes and adjustment. One exception is a study of preadolescents done by Crouter et al. (1990). These researchers found that parental monitoring interacted with both gender and maternal employment status to affect youngsters' self-reported conduct. Specifically, boys in dual-earner families who were less well-monitored scored more poorly on perceived conduct that did all other groups except less well-monitored boys and girls in single-earner families. In other words, less well-monitored boys in dual-earner families scored more poorly on perceived conduct than more well-monitored boys in dual-earner families, and than girls in dual-earner families (regardless of level of parental monitoring). In contrast, less well-monitored girls in dual-earner families did not score more poorly on perceived conduct than girls who were more well-monitored. The authors concluded that parental monitoring may be more important for boys, particularly for boys in dual-earner families. 


\section{THIS STUDY}

The purpose of this study was to examine the associations between parental monitoring and adolescent adjustment from an ecological perspective. To do so, we ran a series of regressions involving parental monitoring, gender, grade level, maternal employment, and adolescent adjustment. Of particular interest were the interactions between parental monitoring and gender, grade level, and maternal employment.

Given the current evidence regarding the associations between parental monitoring and adolescent adjustment, it was expected that, overall, higher levels of parental monitoring would be associated with more positive adolescent adjustment. It was also recognized, however, that parental monitoring might be more consistently associated with adolescents' behavioral adjustment (i.e., sexual activity and minor delinquency) and school functioning (i.e., GPA) than with their emotional adjustment (i.e., depression).

It was further hypothesized that the associations between parental monitoring and adolescent adjustment would be moderated by certain person characteristics (i.e., gender and grade level). Specifically, associations between parental monitoring and adolescent adjustment were expected to increase, in general, with age, and to be strongest during the early high school years (i.e., Grades 9 and 10) than during either the junior high school years (i.e., 7th and 8th grade) or the later high school years (i.e., 11 th and 12th grade). We also anticipated that parental monitoring would have differing associations with adolescent adjustment for boys and girls, but given inconsistencies in the current literature, the direction of these gender differences was not specified a priori. Moreover, we hypothesized that the direction of gender differences might also depend on grade level, mother's work status, or both.

Finally, we expected that mothers' work status would moderate the associations between family processes and adolescent adjustment, but only among boys. Specifically, based on the Crouter et al. (1990) study, parental monitoring was expected to have stronger associations with adjustment for male adolescents whose mothers worked full time than for boys whose mothers worked part time or not at all.

\section{METHOD}

\section{Sample}

Participants were 424 adolescents from a single rural school district in central Pennsylvania. The sample included 197 boys and 227 girls in Grades 7 
through 12 (89 seventh graders, 90 eighth graders, 69 ninth graders, 68 tenth graders, 57 eleventh graders, 51 twelfth graders). All adolescents were White and came from predominantly lower to middle class backgrounds as indexed by parent educational attainment and parent occupational prestige. According to adolescent reports, only $40 \%$ of mothers and $44 \%$ of fathers received more than a high school education. Occupational prestige scores for parents' jobs ranged from 17 to 78 for mothers, and 18 to 81 for fathers, using the 1980 National Opinion Research Center rating system (Stevens \& Hoisington, 1987). The average occupational prestige rating for both mothers and fathers was approximately 40 , which was roughly the national average for both men and women in the 1980 labor force (Stevens \& Hoisington, 1987). Complete data on the independent variables were available for 375 ( $88 \%$ ) of adolescents, although the sample size for each analysis varies slightly, ranging from $N=348$ to $N=375$.

Data collection occurred during the fall of 1992. All parents of students in Grades 7 to 12 were sent letters describing the study and inviting their children to participate. Parents responded using stamped, preaddressed envelopes enclosed with the consent form. Approximately 1,047 students were enrolled in the school district during the time of the study. Only those adolescents whose parents gave written consent and who themselves agreed to participate were included in the study. This active consent procedure yielded a response rate of just over $40 \%$.

\section{Procedure}

Because of its length, the self-report questionnaire was divided into three parts, which were given on 3 separate days in school. A make-up day was also included to increase the number of students completing all three parts. Each part of the survey took approximately $50 \mathrm{~min}$ to complete, and adolescents completed them during their study hall or free periods, or in some cases, during physical education class. A free classroom was reserved for survey administration. Two investigators were present on each occasion to administer the surveys and to answer any questions. No teachers or school administrators were present.

\section{Measures}

The three-part questionnaire included a broad array of measures assessing adolescent mental health and health-related behaviors. Measures used in this study included demographic variables, person characteristics (gender 
and age), context characteristics (maternal employment), parental monitoring, and adolescent outcomes.

\section{Demographic Variables}

Because we reasoned that demographic factors might be related to level of parental monitoring, all analyses in this study controlled for socioeconomic status (SES) and family structure.

SES. The SES composite was created using adolescent reports of parent education level and occupational prestige. For parent education level, adolescents reported how far each of their parents had gone in school. Responses ranged from 1 (grade school education) to 6 (college education). For parent occupational prestige, adolescents also reported the type of job that their mothers and fathers currently held. Responses were coded using the occupational prestige ratings developed by the National Opinion Research Center (cited in Stevens \& Hoisington, 1987), with higher scores representing greater occupational prestige. Adolescents whose parents were unemployed (including students and homemakers) or who reported nonvalid data for this item were given missing values. The four items (mother education, father education, mother occupation, and father occupation) were averaged together to create a single scale score. Because the educational items and the occupational items were on different scales, items were first standardized, then the mean of the four items was calculated.

Family structure. Family structure was assessed using a single question regarding with whom the adolescents currently lived. Responses were categorical and indicated residence with both biological parents, mother only, father only, grandparents, other relatives, adoptive parents, foster parents, friends, or alone. For this analyses, responses were dichotomized to represent those adolescents who lived with both biological parents (traditional families, $n=272$ ) and those who lived in any other family type (nontraditional families, $n=103$ ); the numbers of adolescents reporting particular forms of nontraditional family arrangements were too small to permit separate treatment. This dummy variable (1 [traditional families] and 0 [nontraditional families]) was used as a control in all regression analyses. 


\section{Gender and Grade}

Adolescents reported their gender and current grade level. Gender was coded as 0 (boys) and 1 (girls). Grade level was coded as 7 to 12 . Grade level was centered around 0 for all analyses involving interactions to avoid problems of collinearity (Cohen \& Cohen, 1983). Because we hypothesized that parental monitoring would be of most importance during midadolescence (i.e., a curvilinear effect), a quadratic term was also created by squaring the (centered) grade variable.

\section{Maternal Employment}

Adolescents reported whether their mothers worked full time (61\%), part time $(20 \%)$, or not at all (19\%). For regression analyses, two dummy variables were created: "NOWORK" in which adolescents whose mothers did not work were assigned a score of 1 , and all others were assigned a score of 0 ; and "FULLTIME" in which adolescents whose mother worked full time were assigned a score of 1 , and all others were assigned a score of 0 .

\section{Parental Monitoring}

Students completed an eight-item parental monitoring scale, similar to those used by other investigators (e.g., Brown et al., 1993). Adolescents reported how often their parents knew where they were and what they were doing after school, on weeknights, and on weekends; they also reported whether their parents knew their friends and how often their parents knew if they had completed their homework. All items used a 4-point scale ranging from 1 (almost never), to 2 (sometimes), to 3 (usually), to 4 (almost always). Individual items were averaged to yield a scale score ranging from 1 (low levels of parental monitoring) to 4 (high levels of parental monitoring), with an overall mean of $3.27(S D=0.58)$. Internal consistency was high (Cronbach's $\alpha=.85$ for boys, and .86 for girls). Parental monitoring was centered for all analyses involving interactions to avoid problems of collinearity (Cohen \& Cohen, 1983).

\section{Adolescent Outcome Variables}

Four dimensions of adolescent adjustment were assessed, including minor delinquency, sexual activity, emotional adjustment (depression), and school functioning. 
Minor delinquency. Minor delinquency was assessed using a seven-item scale consisting of stole something worth less than $\$ 5$, stole something worth between $\$ 5$ and $\$ 50$, disobeyed parents, got in trouble at school, skipped school, damaged someone else's property, and physically hurt someone else on purpose. The items were drawn from several delinquency scales (e.g., Huizinga, Esbensen, \& Weiher, 1991; Swisher, Shute, \& Bibeau, 1984). Adolescents responded using a 6-point scale ranging from 1 (not at all) to 6 (more than 20 times) to indicate the frequency with which they had engaged in these behaviors during the past 6 months. All seven items loaded on a single factor in an exploratory factor analysis. The scale also showed satisfactory internal consistency (Cronbach's $\alpha=.76$ for boys, and .85 for girls). Items were averaged to create a single scale score ranging from 1 (low levels of minor delinquency) to 6 (high levels of minor delinquency), with an overall mean of $1.66(S D=0.64)$.

Sexual activity. Adolescents used a 6-point scale ranging from 1 (not at all) to 6 (more than 20 times) to indicate the number of times during the past 6 months that they had engaged in each of seven sexual behaviors, ranging from going on a date to having sex. In an exploratory factor analysis, all seven items loaded on a single factor. Additionally, internal consistency was quite high (Cronbach's $\alpha=.97$ for boys, and .96 for girls). Items were averaged to create a single scale score ranging from 1 (low levels of sexual activity) to 6 (high levels of sexual activity), with an overall mean of $2.44(S D=1.63)$.

Emotional adjustment. Emotional adjustment was assessed using Kandel's Depression Inventory (Kandel \& Davies, 1982). This instrument assesses six common symptoms of depression (e.g., sadness, anxiety, sleeplessness, etc.). Responses were coded on a 4-point frequency scale ranging from 1 (never) to 4 (most of the time). Reliability and validity for this scale have been demonstrated elsewhere (Kandel \& Davies, 1982), and internal consistency for this sample was satisfactory (Cronbach's alpha for this scale $=.70$ for boys, and .75 for girls). Items were averaged to create a single scale score ranging from 1 (not depressed) to 4 (very depressed), with a mean of 2.05 $(S D=0.50)$.

School functioning. School achievement was measured using adolescent self-reported GPA. Adolescents reported grades from their last report card for Math, English, Science, and Social Studies on a standard 4-point scale ranging from $4(A)$ to $0(F)$. Items were then averaged to create an overall measure of GPA $(M=3.15, S D=.81)$. Other investigators have found 
self-reports of grade to correlate highly with actual grades taken from school transcripts (Crockett, Schulenberg, \& Petersen, 1987; Donovan \& Jessor, 1985; Dornbusch et al., 1987).

\section{RESULTS}

\section{Preliminary Analyses}

Two two-way analyses of variance were conducted to determine whether level of parental monitoring varied by gender and grade level, and/or by gender and maternal employment status. ${ }^{1}$ No significant effects were found for either grade level or maternal employment group. There was, however, a significant main effect of gender, $F(1,341)=30.1, p<.001$. On average, girls reported higher levels of parental monitoring than boys $(M=$ $3.38, S D=.53$ for girls; $M=3.13, S D=.60$ for boys). Neither of the interactions with gender was significant.

\section{Intercorrelations Among Variables}

Table 1 shows the intercorrelations among SES, family structure (traditional vs. other configurations), parental monitoring, and the outcome variables. SES was positively correlated with GPA for both genders, and was negatively correlated with depressed mood for girls and with sexual activity for boys. However, it was not related to level of parental monitoring for either gender. Family structure was related to sexual activity for both genders, with adolescents in non-two-parent biological families reporting higher levels of sexual behavior. It was also correlated with GPA among boys: Boys in traditional two-parent families reported higher grades than those in other family structures. Finally, family structure was correlated with parental monitoring but only among girls: Girls living with both biological parents reported higher levels of monitoring than girls in other family configurations.

As expected, parental monitoring was significantly correlated with adolescent adjustment. For sexual activity, delinquency, and GPA, the association was significant for both genders; for depressed mood, it was

\footnotetext{
${ }^{1}$ Three-way analyses of variance with gender, grade level, and maternal employment could not be conducted, due to the presence of a number of very small cell sizes (i.e., less than 5 cases). This is also partly the reason why the moderating effects of gender and grade level, and gender and maternal employment are examined separately.
} 
TABLE 1

Intercorrelations Among SES, Parental Monitoring, and Dependent Variables

\begin{tabular}{|c|c|c|c|c|c|c|c|}
\hline & SES & $\begin{array}{c}\text { Family } \\
\text { Structure }\end{array}$ & Monitoring & Delinquency & $\begin{array}{c}\text { Sexual } \\
\text { Activity }\end{array}$ & $\begin{array}{c}\text { Depressed } \\
\text { Mood }\end{array}$ & $G P A$ \\
\hline SES & - & .04 & .12 & -.01 & -.09 & $-.16^{*}$ & $.27^{* * *}$ \\
\hline Family structure & .08 & - & $.17^{* *}$ & .03 & $-.16^{*}$ & -.03 & .09 \\
\hline Monitoring & .02 & .10 & - & $-.27^{* * *}$ & $-.25^{* * *}$ & $-.34^{* * *}$ & $.22^{* * *}$ \\
\hline Delinquency & .01 & -.07 & $-.44^{* * *}$ & - & $.27^{* * *}$ & $.18^{* *}$ & $-.23^{* * *}$ \\
\hline Sexual activity & $-.18^{*}$ & $-.16^{*}$ & $-.28^{* * *}$ & $.39^{* * *}$ & - & $.22^{* * *}$ & $-.21^{* *}$ \\
\hline Depressed mood & -.05 & .03 & -.12 & .13 & .03 & - & $-.19^{* *}$ \\
\hline GPA & $.29^{* * *}$ & $.19^{* * *}$ & $.20 * *$ & $-.35^{* * *}$ & $-.38^{* * *}$ & .06 & - \\
\hline
\end{tabular}

Note. Correlations for boys are below the diagonal (Ns =151-172); correlations for girls are above the diagonal $(\mathrm{Ns}=205-216)$. SES = socioeconomic status; GPA = grade point average.

${ }^{*} p<.05 .{ }^{* *} p<.01 .{ }^{* * *} p<.001$.

significant only among girls. The four outcome variables were moderately intercorrelated for both genders, with $r$ s ranging from - -38 to .39 ; the only exception was a nonsignificant correlation between GPA and depression in boys.

\section{Regression Analyses}

Hierarchical multiple-regression analyses were conducted to examine whether the relations between parental monitoring and adolescent adjustment were moderated by either person or context characteristics. Moderation was tested by including interactions between parental monitoring and gender, grade level, and maternal employment. Because a regression involving four-way interactions between parental monitoring, gender, grade level, and maternal employment would have been difficult to interpret (Cohen \& Cohen, 1983), we broke down the analyses into two steps. In the first step, we examined whether the associations between parental monitoring and adolescent adjustment were moderated by gender, grade level, or both. In the second step, we examined whether the associations between parental monitoring and adjustment were moderated by gender, maternal employment, or both. The SES composite variable and the dummy variable for family structure were used as controls in all of the analyses.

Gender and grade level as moderators. Following the suggestions outlined by various statisticians (e.g., Aiken \& West, 1991; Cohen \& Cohen, 1983; Jaccard, Turrisi, \& Wan, 1990), the hierarchical multiple regressions for each outcome were performed in the following manner: In Model 1, the SES variable and the family-structure variable were entered in as controls. 
In Model 2, the main effects of gender and grade were added. Model 3 further added the quadratic effect of grade $\left(\right.$ grade $\left.^{2}\right)$. Model 4 added the main effect of parental monitoring. In Model 5, three two-way interactions were created using gender, grade, and parental monitoring. In Model 6, two more two-way interactions were added (i.e., Parental Monitoring $\times$ Grade $^{2}$ and Gender $\times$ Grade $^{2}$ ). In Model 7, the three-way interaction between gender, grade, and parental monitoring was added, and in the final model (Model 8; the full model), the three-way interaction between gender, grade $^{2}$, and parental monitoring was added. ${ }^{2}$ Results are reported in Tables 2 through 5 .

Results for delinquency appear in Table 2. As can be seen in Table 2, neither SES nor family structure was significantly associated with minor delinquency (Model 1). Boys reported higher levels of delinquency, but grade level was not associated with delinquency (Model 2). The inclusion of gender and grade level explained an additional $6 \%$ of the variance in delinquency $(p<.001)$. The curvilinear effect of grade level was not significant (Model 3). In Model 4, parental monitoring was significant (increase in $R^{2}=.11, p<.001$ ), with higher levels of monitoring predicting less delinquency. None of the two-way interactions (Models 5 and 6) were significant. There was, however, a significant three-way interaction between gender, grade level, and monitoring (Model 7), accounting for an additional $1 \%$ of the variance $(p<.05)$. Finally, the three-way interaction between gender, monitoring, and the curvilinear effect of grade level was not significant (Model 8). The total amount of variance explained by the full model was $18 \%$.

The previous analyses indicate that the association between parental monitoring and adolescent delinquency varied systematically across gender and grade level. We explored the nature of the three-way interaction by using the unstandardized regression coefficients from the full model to create simple slopes for the relation between parental monitoring and adolescent delinquency. Simple slopes were created for six different groups of adolescents: boys and girls in 7th, 9th, and 11th grades (see Aiken \& West, 1991; Cohen \& Cohen, 1983, for details on how simple slopes can be created). ${ }^{3}$ To determine the significance of the simple slopes in each of the six

\footnotetext{
${ }^{2}$ Because gender and grade level (and maternal employment) are assumed to be more exogenous than parental monitoring, according to suggestions given by Cohen and Cohen (1983), parental monitoring was added as a separate step, after the main effects of gender and grade level (or gender and maternal employment). Similarly, Cohen and Cohen (1983) stated that significance of quadratic effects can only be assessed after controlling for linear effects; thus grade $^{2}$ is entered in a separate step after linear grade (but before parental monitoring), and the two- and three-way interactions involving grade ${ }^{2}$ are entered in after the two- and three-way interactions involving the linear grade component.
} 
TABLE 2

Standardized Regression Coefficients for Delinquency: Moderating Influences of Gender and Grade

\begin{tabular}{lcccccccc}
\hline Predictor & Step 1 & Step 2 & Step 3 & Step 4 & Step 5 & Step 6 & Step 7 & Step 8 \\
\hline SES & .00 & .00 & .00 & .02 & .01 & .01 & .01 & .01 \\
Family structure & -.01 & -.01 & -.01 & .02 & .01 & .01 & .02 & .02 \\
Gender & & $-.27^{* *}$ & $-.27^{* *}$ & $-.20^{* *}$ & $-.20^{* *}$ & $-.15^{*}$ & -.15 & -.15 \\
Grade & & .01 & .01 & -.01 & .09 & .08 & .07 & .06 \\
Grade & & & -.02 & .02 & .02 & .07 & .06 & .07 \\
Monitoring & & & & $-.34^{* *}$ & $-.42^{* *}$ & $-.42^{* *}$ & $-.42^{* *}$ & $-.44^{* *}$ \\
MON $\times$ GEN & & & & & .10 & .11 & .11 & .12 \\
MON $\times$ GRD & & & & & -.05 & -.05 & $-.17^{*}$ & $-.17^{*}$ \\
GEN $\times$ GRD & & & & & -.12 & -.11 & -.12 & -.12 \\
MON $\times$ GRDSQ & & & & & & -.01 & .01 & .03 \\
GEN $\times$ GRDSQ & & & & & & -.07 & -.07 & -.07 \\
MON $\times$ GEN $\times$ GRD & & & & & & & .17 & $.17^{*}$ \\
MON $\times$ GEN $\times$ GRDSQ & & & & & & & & -.02 \\
$R^{2}$ & .00 & .08 & .08 & .18 & .20 & .20 & .21 & .21 \\
Adjusted $R^{2}$ & .00 & .06 & .06 & .17 & .18 & .18 & .19 & .18 \\
Model F statistic & 0.01 & $7.12^{* *}$ & $5.71^{* *}$ & $13.12^{* *}$ & $9.62^{* *}$ & $7.89^{* *}$ & $7.80^{* *}$ & $7.18^{* *}$ \\
$F$ change & - & $14.22^{* *}$ & 0.16 & $46.48^{* *}$ & 2.31 & 0.29 & $5.65^{*}$ & 0.04 \\
\hline
\end{tabular}

Note. $N=357 . \mathrm{SES}=$ socioeconomic status; $\mathrm{GEN}=$ gender; $\mathrm{GRD}=$ grade; $\mathrm{GRDSQ}=$ grade squared; $\mathrm{MON}=$ monitoring.

${ }^{*} p<.05 .{ }^{* *} p<.01$.

groups, we also computed the standard errors around the estimate for the simple slope (see Aiken \& West, 1991) and conducted $t$ tests. Figures 1 and 2 graph the relations between monitoring and delinquency for girls and boys (respectively) in the three different age groups.

As can be seen in Figures 1 and 2, higher levels of parental monitoring were associated with lower levels of delinquent behavior for adolescents in all six groups. However, among girls, the relation between parental monitoring and delinquency was strongest for the youngest adolescents (i.e., the 7th graders), and weakest among the oldest adolescents (i.e., the 11th graders; see Figure 1). The simple slopes for 7th-, 9 th-, and 11th-grade girls were $-.41(S E=.14, p<.01),-.30(S E=.11, p<.01)$, and $-.22(S E=.13, p$ $<.05)$, respectively. Among boys, the reverse was true: The relation between monitoring and delinquency was strongest among the oldest adolescents and weakest among the youngest adolescents (see Figure 2). The

\footnotetext{
${ }^{3}$ Because grade level is a meaningful variable, we used 7 th, 9 th, and 11 th grade to represent early, middle, and late adolescence, respectively. The average grade level in the sample was $9.2(S D=1.7)$, so 7 th and 11th grade represents adolescents approximately $1 S D$ below and 1 $S D$ above the mean, respectively.
} 
simple slopes for 7th-, 9th-, and 11th-grade boys were -.21 (SE $=.12, p<$ $.05),-.47(S E=.12, p<.001)$, and -.67 (SE = .14, $p<.001)$, respectively. Thus, the relation between monitoring and delinquency, although significant in all six groups, increased with age for boys, but decreased with age for girls.

Table 3 presents the results for adolescent sexual behavior. Higher levels of SES and being in a two-parent family were both significantly associated with lower levels of sexual activity (Model $1 ; R^{2}=.04, p<.001$ ). The addition of gender and grade (Model 2) was also significant $\left(\Delta R^{2}=.16, p<\right.$ .001). The association between grade level and sexual activity was positive, indicating that levels of sexual behavior increased with age; however, gender was not related to sexual activity. The addition of the curvilinear effect of grade (Model 3) was not significant. The addition of parental monitoring (Model 4) explained an additional 5\% of the variance in sexual activity $(p<.001)$, with higher levels of monitoring associated with less sexual activity. The addition of the interaction terms (Models 5-8) was not significant. Thus, the results from these analyses indicate that higher levels of monitoring were associated with less sexual activity, and that these associ-

TABLE 3

Standardized Regression Coefficients for Sexual Behavior:

Moderating Influences of Gender and Grade

\begin{tabular}{lcccccccc}
\hline Predictor & Step 1 & Step 2 & Step 3 & Step 4 & Step 5 & Step 6 & Step 7 & Step 8 \\
\hline SES & $-.12^{*}$ & $-.14^{* *}$ & $-.14^{* *}$ & $-.12^{* *}$ & $-.12^{* *}$ & $-.12^{* *}$ & $-.12^{* *}$ & $-.12^{* *}$ \\
Family structure & $-.16^{* * *}$ & $-.16^{* * *}$ & $-.16^{* * *}$ & $-.14^{* *}$ & $-.14^{* *}$ & $-.13^{* *}$ & $-.13^{* *}$ & $-.12^{* *}$ \\
Gender & & -.03 & -.03 & .02 & .02 & -.01 & -.01 & .00 \\
Grade & & $.41^{* * *}$ & $.40^{* * *}$ & $.39^{* * *}$ & $.33^{* * *}$ & $.34^{* * *}$ & $.33^{* * *}$ & $.33^{* * *}$ \\
Grade & & & .02 & .05 & .05 & .02 & .02 & .03 \\
Monitoring & & & & $-.24^{* * *}$ & $-.25^{* * *}$ & $-.30^{* * *}$ & $-.31^{* * *}$ & $-.38^{* * *}$ \\
MON $\times$ GEN & & & & & .03 & .02 & .02 & .13 \\
MON $\times$ GRD & & & & & -.03 & -.04 & -.11 & -.13 \\
GEN $\times$ GRD & & & & & .09 & .08 & .07 & .07 \\
MON $\times$ GRDSQ & & & & & & .07 & .08 & .17 \\
GEN $\times$ GRDSQ & & & & & & .05 & .05 & .05 \\
MON $\times$ GEN $\times$ GRD & & & & & & & .10 & .13 \\
MON $\times$ GEN $\times$ GRDSQ & & & & & & & & -.15 \\
$R^{2}$ & .04 & .21 & .21 & .26 & .27 & .27 & .27 & .28 \\
Adjusted $R^{2}$ & .04 & .20 & .20 & .25 & .25 & .25 & .25 & .25 \\
Model F statistic & $8.02^{* * *}$ & $24.56^{* * *}$ & $19.66^{* * *}$ & $21.62^{* * *}$ & $29.67^{* * *}$ & $12.06^{* * *}$ & $22.89^{* * *}$ & $10.59^{* * *}$ \\
F change & - & $39.44^{* * *}$ & 0.25 & $25.03^{* * *}$ & 0.66 & 0.75 & 2.24 & 1.97 \\
\hline
\end{tabular}

Note. $N=374$. SES = socioeconomic status; GEN = gender; GRD = grade; GRDSQ = grade squared; $\mathrm{MON}=$ monitoring.

${ }^{*} p<.05 .{ }^{* *} p<.01 .{ }^{* *} p<.001$. 
ations did not differ by gender or grade level. The full model explained $25 \%$ of the variance in sexual activity.

Results for adolescent depressed mood are shown in Table 4. Higher SES was significantly and inversely associated with depressed mood, although family structure was not related to depressed mood (Model 1). Although grade level was not significantly related to depressed mood, being a girl was associated with higher levels of depressed $\operatorname{mood}\left(\right.$ Model $2 ; \Delta R^{2}=$ $.05, p<.001$ ). The curvilinear effect of grade was not significant (Model 3). Monitoring was significantly associated with depressed mood, with higher levels of monitoring associated with lower levels of depressed mood (Model $4 ; \Delta R^{2}=.04, p<.001$ ). Although the two-way interaction between gender and monitoring was significant, the addition of all two-way interactions as a set (Models 5 and 6) did not account for a significant increase in variance, nor did the addition of the three-way interactions (Models 7 and 8). Thus, higher levels of monitoring were significantly related to lower levels of depressed mood, but this association was not moderated by gender or grade level. The full model explained $11 \%$ of the variance.

TABLE 4

Standardized Regression Coefficients for Depressed Mood:

Moderating Influences of Gender and Grade

\begin{tabular}{lcccccccc}
\hline Predictor & Step 1 & Step 2 & Step 3 & Step 4 & Step 5 & Step 6 & Step 7 & Step 8 \\
\hline SES & $-.13^{*}$ & $-.14^{* *}$ & $-.14^{* *}$ & $-.12^{*}$ & $-.12^{*}$ & $-.12^{*}$ & $-.12^{*}$ & $-.11^{*}$ \\
Family structure & .00 & .00 & .00 & .03 & .03 & .03 & .02 & .03 \\
Gender & & $.21^{* * *}$ & $.21^{* * *}$ & $.26^{* * *}$ & $.26^{* * *}$ & $.33^{* * *}$ & $.33^{* * *}$ & $.33^{* * *}$ \\
Grade & & $.11^{*}$ & $.11^{*}$ & .10 & .11 & .09 & .09 & .09 \\
Grade & & & -.03 & .01 & .01 & .08 & .08 & .10 \\
Monitoring & & & & $-.22^{* * *}$ & -.11 & -.08 & -.14 & -.17 \\
MON $\times$ GEN & & & & & $-.16^{*}$ & $-.14^{*}$ & $-.14^{*}$ & -.02 \\
MON $\times$ GRD & & & & & -.04 & -.03 & .01 & -.02 \\
GEN $\times$ GRD & & & & & -.01 & .02 & .02 & .02 \\
MON $\times$ GRDSQ & & & & & & -.05 & -.05 & .07 \\
GEN $\times$ GRDSQ & & & & & & -.12 & -.12 & -.11 \\
MON $\times$ GEN $\times$ GRD & & & & & & & -.06 & -.02 \\
MON $\times$ GEN $\times$ GRDSQ & & & & & & & & -.18 \\
$R^{2}$ & .02 & .07 & .07 & .11 & .13 & .13 & .13 & .14 \\
Adjusted $R^{2}$ & .01 & .06 & .06 & .10 & .11 & .11 & .11 & .11 \\
Model F statistic & 2.95 & $7.05^{* * *}$ & $5.68^{* * *}$ & $7.88^{* * *}$ & $5.93^{* * *}$ & $5.06^{* * *}$ & $4.68^{* * *}$ & $4.55^{* * *}$ \\
$F$ change & - & $10.99^{* * *}$ & 0.24 & $17.64^{* * *}$ & 1.91 & 1.11 & 0.62 & 2.72 \\
\hline
\end{tabular}

Note. $N=375 ;$ SES = socioeconomic status; $\mathrm{GEN}=$ gender; $\mathrm{GRD}=$ grade; $\mathrm{GRDSQ}=$ grade squared; $\mathrm{MON}=$ monitoring.

${ }^{*} p<.05 .{ }^{* *} p<.01 .{ }^{* * *} p<.001$. 


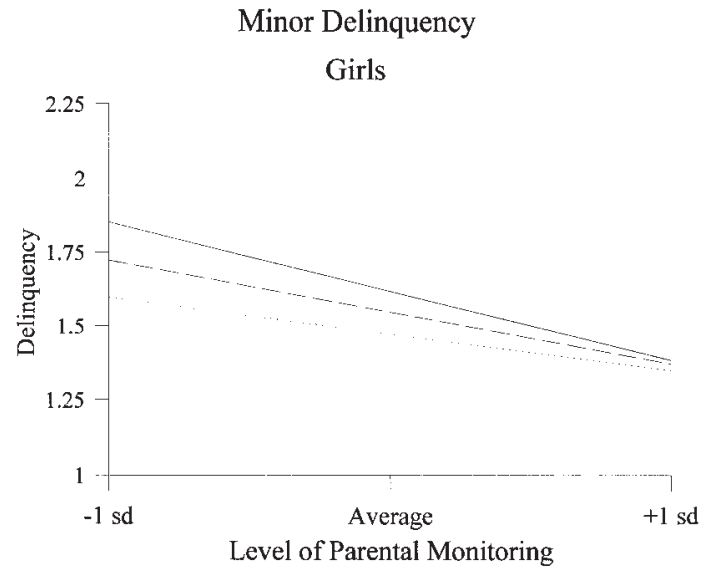

7th grade $\ldots \ldots . . . . \quad 9$ th grade $\quad \ldots \ldots \quad 11$ th grade

FIGURE 1 The relations between monitoring and delinquency among girls at three different grade levels. Slopes for all three groups are significant at the $p<.05$ level.

Table 5 shows the results for adolescent GPA. Both SES and family structure (Model 1) were significantly associated with GPA and together explained $9 \%$ of the variance. Higher SES and two-parent family structure were each related to higher GPA. Grade level was not significantly related to GPA, but being a girl was associated with higher GPA (Model $2 ; \Delta R^{2}=.04, p<$

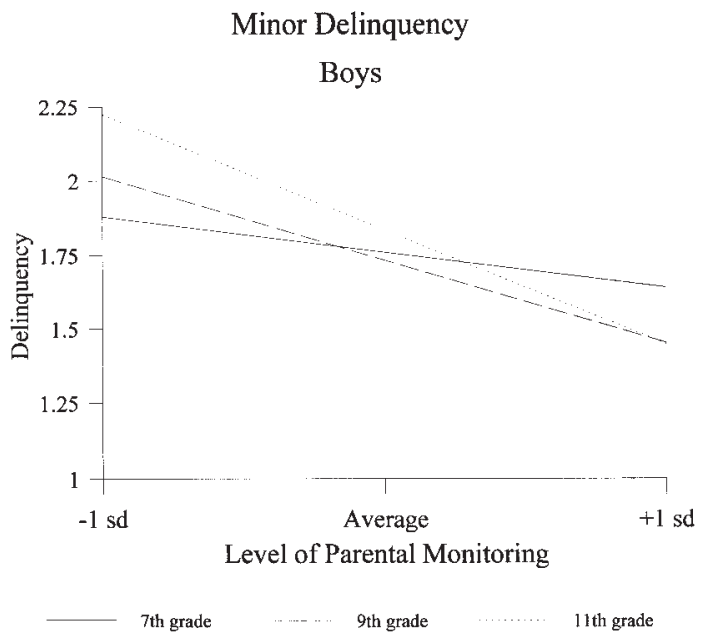

FIGURE 2 The relations between monitoring and delinquency among boys at three different grade levels. Slopes for all three groups are significant at the $p<.05$ level. 
TABLE 5

Standardized Regression Coefficients for Grade Point Average: Moderating Influences of Gender and Grade

\begin{tabular}{lcccccccc}
\hline Predictor & Step 1 & Step 2 & Step 3 & Step 4 & Step 5 & Step 6 & Step 7 & Step 8 \\
\hline SES & $.28^{* * *}$ & $.28^{* * *}$ & $.29^{* * *}$ & $.28^{* * *}$ & $.28^{* * *}$ & $.28^{* * *}$ & $.28^{* * *}$ & $.28^{* * *}$ \\
Family structure & $.12^{*}$ & $.12^{*}$ & $.11^{*}$ & $.10^{*}$ & $.10^{*}$ & $.11^{*}$ & $.10^{*}$ & $.10^{*}$ \\
Gender & & $.18^{* * *}$ & $.19^{* * *}$ & $.15^{* *}$ & $.15^{* *}$ & $.21^{* *}$ & $.20^{* *}$ & $.20^{* *}$ \\
Grade & & -.06 & $-.11^{*}$ & -.10 & -.13 & -.14 & -.13 & -.13 \\
Grade & & & $.14^{* *}$ & $.12^{*}$ & $.12^{*}$ & $.18^{*}$ & $.18^{*}$ & .17 \\
Monitoring & & & & $.15^{* *}$ & $.18^{* *}$ & .10 & .12 & .19 \\
MON $\times$ GEN & & & & & -.04 & -.03 & -.04 & -.12 \\
MON $\times$ GRD & & & & & -.04 & -.05 & .04 & .06 \\
GEN $\times$ GRD & & & & & .05 & .07 & .08 & .08 \\
MON $\times$ GRDSQ & & & & & & .10 & .08 & .00 \\
GEN $\times$ GRDSQ & & & & & & -.10 & -.09 & -.10 \\
MON $\times$ GEN $\times$ GRD & & & & & & & -.13 & $-.15^{*}$ \\
MON $\times$ GEN $\times$ GRDSQ & & & & & & & & .11 \\
$R^{2}$ & .10 & .14 & .15 & .18 & .18 & .18 & .19 & .19 \\
Adjusted $R^{2}$ & .09 & .13 & .14 & .16 & .16 & .16 & .16 & .16 \\
Model F statistic & $18.94^{* * * *}$ & $13.56^{* * *}$ & $12.51^{* * *}$ & $12.20^{* * *}$ & $8.22^{* * *}$ & $6.89^{* * *}$ & $6.63^{* * *}$ & $6.20^{* * *}$ \\
$F$ change & - & $7.47^{* * *}$ & $7.33^{* *}$ & $9.16^{* *}$ & 0.38 & 0.94 & 3.28 & 1.01 \\
\hline
\end{tabular}

Note. $N=352 ; \mathrm{SES}=$ socioeconomic status; $\mathrm{GEN}=$ gender; $\mathrm{GRD}=$ grade; $\mathrm{GRDSQ}=$ grade squared $\mathrm{MON}=$ monitoring.

${ }^{*} p<.05 .{ }^{* *} p<.01 .{ }^{* * *} p<.001$.

.001). The curvilinear effect of grade was also significant (Model 3) and increased the $R^{2}$ by $1 \%(p<.01)$. Inspection of the means revealed that average GPA decreased from 7 th to 11 th grade, but then increased among 12 th graders. Higher levels of monitoring were significantly associated with higher GPA (Model $4 ; \Delta R^{2}=.02, p<.01$ ), but neither the addition of the two-way interactions (Models 5 and 6) nor the addition of the three-way interactions (Models 7 and 8) significantly increased the $R^{2}$. Thus, the relation between monitoring and GPA was not moderated by gender or grade level. The full model explained $16 \%$ of the variance in GPA. The results from all four of the hierarchical regression indicate that parental monitoring was significantly associated with all indexes of adolescent adjustment. Higher levels of monitoring were associated with higher GPA and lower levels of delinquency, sexual activity, and depressed mood. However, there was little evidence that the relation between monitoring and adjustment was moderated by gender and grade level. Clear evidence of such moderating effects appeared only for delinquency; in this case the relation was moderated by a combination of gender and grade level. More precisely, the interaction between grade level and monitoring differed for boys and girls: Although better 
monitoring was associated with lower delinquency for boys and girls at all grade levels, the strongest relations between monitoring and delinquency appeared at different grade levels for the two genders.

Gender and maternal employment as moderators. To explore the joint moderation of gender and maternal employment on the relation between parental monitoring and adjustment, a five-step hierarchical multiple regression was conducted for each outcome. Similar to the preceding analyses, Model 1 included only the SES variable and family-structure variables and Model 2 added the main effects of gender and maternal employment (with maternal employment coded as two dummy variables). Model 3 further added the main effect of parental monitoring. In Model 4, the two-way interactions involving gender, maternal employment, and parental monitoring were added. Finally, Model 5 added the three-way interactions between gender, maternal employment, and parental monitoring.

The results for delinquency are shown in Table 6. As reported for the preceding analyses, neither SES nor family structure was associated with delinquency (Model 1). The addition of gender and the two maternal employment dummy variables increased the $R^{2}$ by $6 \%(p<.001)$. As before, boys reported significantly higher levels of delinquency; however, neither of the two maternal employment variables was significant. Monitoring explained an additional $11 \%$ of the variance in delinquency $(p<.001$; Model $3)$, with higher levels of monitoring associated with lower delinquency. The addition of the two-way interactions (Model 4), did not account for a significant increase in variance. However, the addition of the two three-way interactions was significant $\left(\Delta R^{2}=.02, p<.05\right.$; Model 5$)$. The full model explained $19 \%$ of the variance.

To interpret the direction of the three-way interaction, we used the unstandardized regression coefficients to create the simple slopes (see Aiken \& West, 1991) for boys and girls in the three different maternal employment groups-full time, part time, and not working. The simple slopes are plotted in Figure 3 (boys) and Figure 4 (girls). For both boys and girls whose mothers worked full time, higher levels of parental monitoring were associated with lower sexual behavior $(b=-.50, S E=.10, p<.002$, for boys; $b=-.36, S E=.18, p<.05$, for girls). Among adolescents whose mothers worked part time, the relation between monitoring and delinquency was significant only for boys $(b=-.76, S E=.19, p<.001$, for boys; $b=.01, S E$ $=.17, p>.99$, for girls). In contrast, among adolescents whose mothers were not employed, the relation between monitoring and delinquency was only significant among girls $(b=-.20, S E=.17, p>.10$, for boys; $b=-.39, S E=.18$, $p<.05)$. In sum, higher levels of monitoring were significantly related to lower levels of delinquency among boys whose mothers were employed 


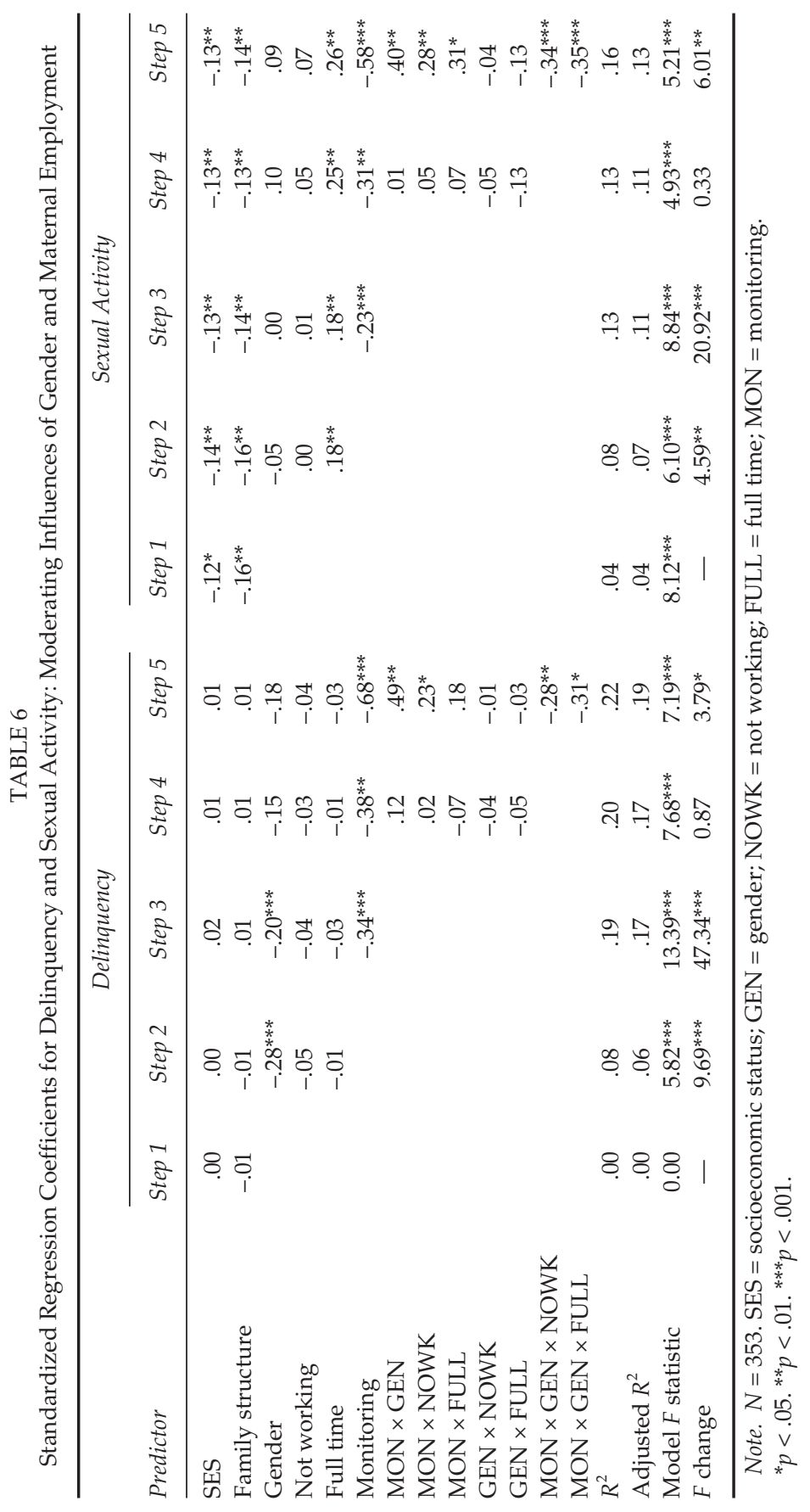




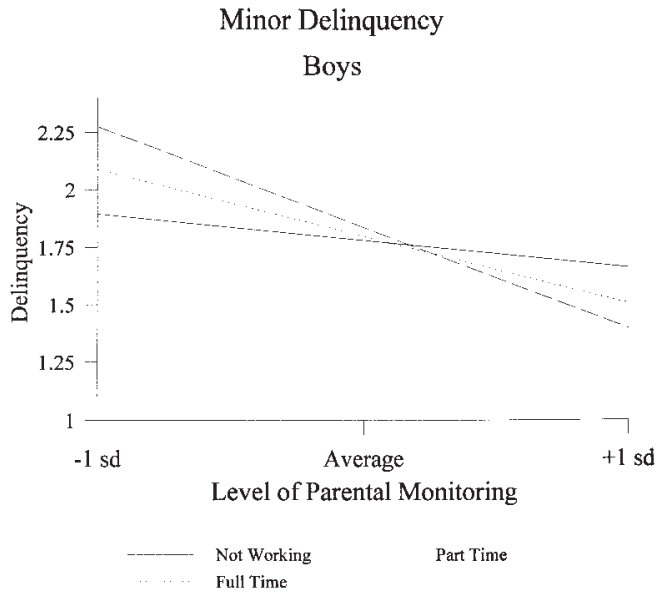

FIGURE 3 The relations between monitoring and delinquency among boys in different maternal employment groups. Slopes for the full-time and part-time groups are significant at the $p<.05$ level. The slope for the not-working group is not significant.

(either full or part time) and among girls whose mothers either worked full time or did not work outside the home.

The results for sexual activity are also shown in Table 6. As with the regression involving gender and grade level, both control variables were significantly related to sexual activity: Higher SES and being in a two-parent

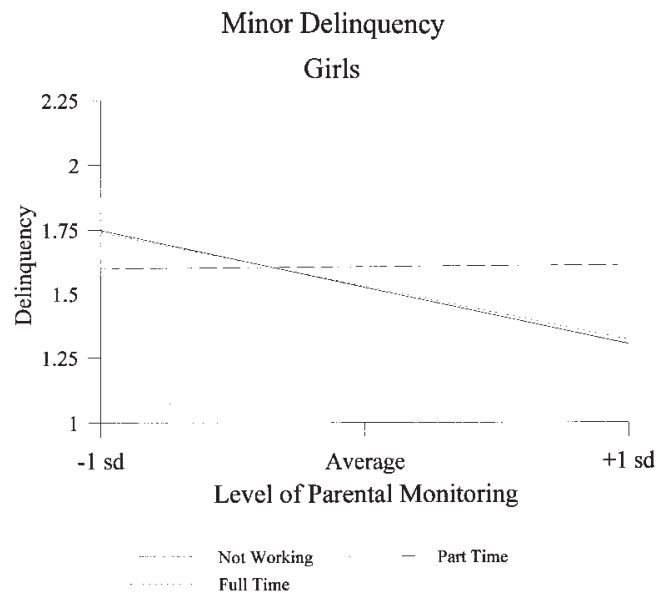

FIGURE 4 The relations between monitoring and delinquency among girls in different maternal employment groups. Slopes for the full-time and not-working groups are significant at the $p<.05$ level. The slope for the part-time group is not significant. 
family were associated with less sexual activity $\left(R^{2}=.04, p<.001\right)$. The addition of gender and the two maternal employment variables was also significant $\left(\Delta R^{2}=.02, p<.01\right)$. Gender was not associated with level of sexual activity, but sexual activity was greater among adolescents whose mothers worked full time (Model 2). Monitoring had a significant main effect for sexual activity (Model 3), with higher levels of monitoring associated with less sexual activity $\left(\Delta R^{2}=.04, p<.001\right)$. The addition of the two-way interactions (Model 4), did not account for any additional variance. However, the addition of the two three-way interactions was significant (Model 5), and explained an additional $2 \%$ of the variance in sexual activity $(p<.01)$. The full model explained $13 \%$ of the variance.

Figures 5 and 6 show the strength of the relation between parental monitoring and sexual activity among adolescents in the three maternal employment groups. Figures 5 and 6 depict the relations for boys and girls, respectively. Examination of the simple slopes revealed a pattern similar to that just described for delinquency. Specifically, higher parental monitoring was significantly associated with less sexual activity among both boys and girls whose mothers worked full time $(b=-.50, S E=.27, p<.05$, for boys; $b=$ $-.70, S E=.26, p<.01$, for girls), among boys (but not girls) whose mothers worked part time $(b=-1.67, S E=.42, p<.001$, for boys; $b=-.02, S E=.44, p>$ .90 , for girls), and among girls (but not boys) whose mothers did not work ( $b$ $=-1.29, S E=.26, p<.05$, for girls; $b=.25, S E=.53, p>.80$, for boys).

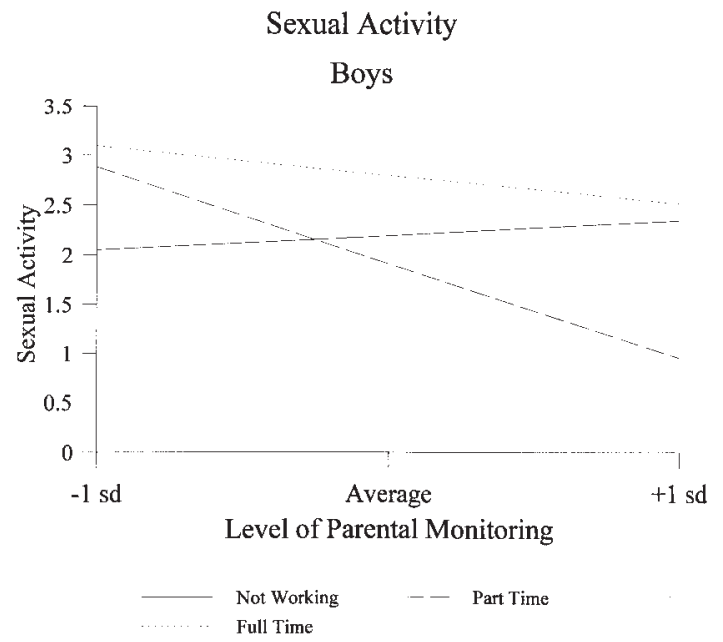

FIGURE 5 The relations between monitoring and sexual activity among boys in different maternal employment groups. Slopes for the full-time and part-time groups are significant at the $p<.05$ level. The slope for the not-working group is not significant. 


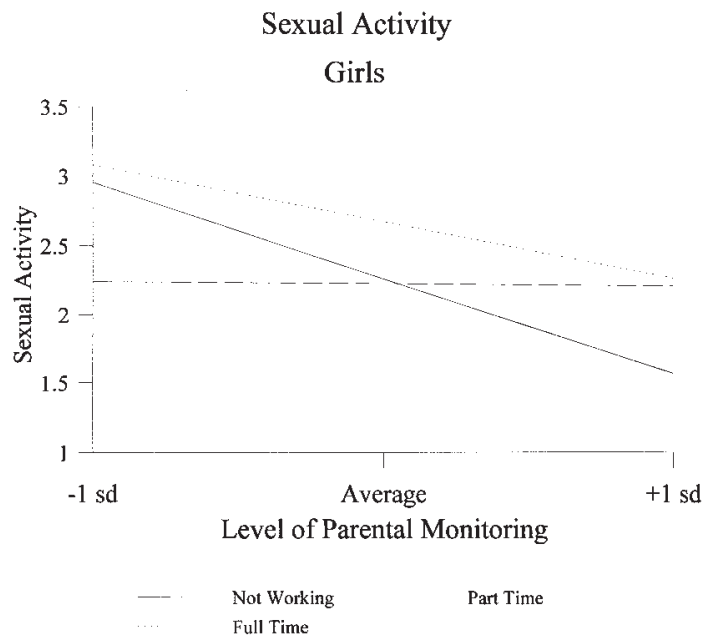

FIGURE 6 The relations between monitoring and sexual activity among girls in different maternal employment groups. Slopes for the full-time and not-working groups are significant at the $p<.05$ level. The slope for the part-time group is not significant.

The results for adolescent depressed mood are summarized in Table 7. SES was significantly, inversely related to depressed mood, but family structure was not (Model $1 ; R^{2}=.01, p<.05$ ). The addition of gender and the maternal employment dummy variables increased the $R^{2}$ significantly $\left(\Delta R^{2}=.04, p<.001\right.$; Model 2). Girls reported higher levels of depressed mood than boys, but there were no main effects of maternal employment. The addition of parental monitoring was also significant $\left(\Delta R^{2}=.05, p<\right.$ .001; Model 3); higher levels of monitoring were associated with less depressed mood. Adding the two-way interactions did not significantly increase the $R^{2}$, although the two-way interaction between monitoring and gender was significant (Model 4). The addition of the three-way interactions also did not contribute significantly to the variance explained (Model 5). The full model explained $10 \%$ of the variance.

Finally, the results for GPA are also shown in Table 7. The model with only the control variables was significant (Model $1 ; R^{2}=.10, p<.001$ ): Two-parent families and higher SES were both associated with higher GPA. The addition of gender and grade level increased the $R^{2}$ by $.03(p<$ .001; Model 2). The effect of gender was significant, with girls reporting higher GPAs than boys; however, the maternal employment variables were not significant. Higher monitoring was associated with higher GPA (Model 3), and explained an additional $2 \%$ of the variance $(p<.001)$. The addition of the two-way interactions did not yield a significant increase in variance explained (Model 4), even though the two-way interaction be- 


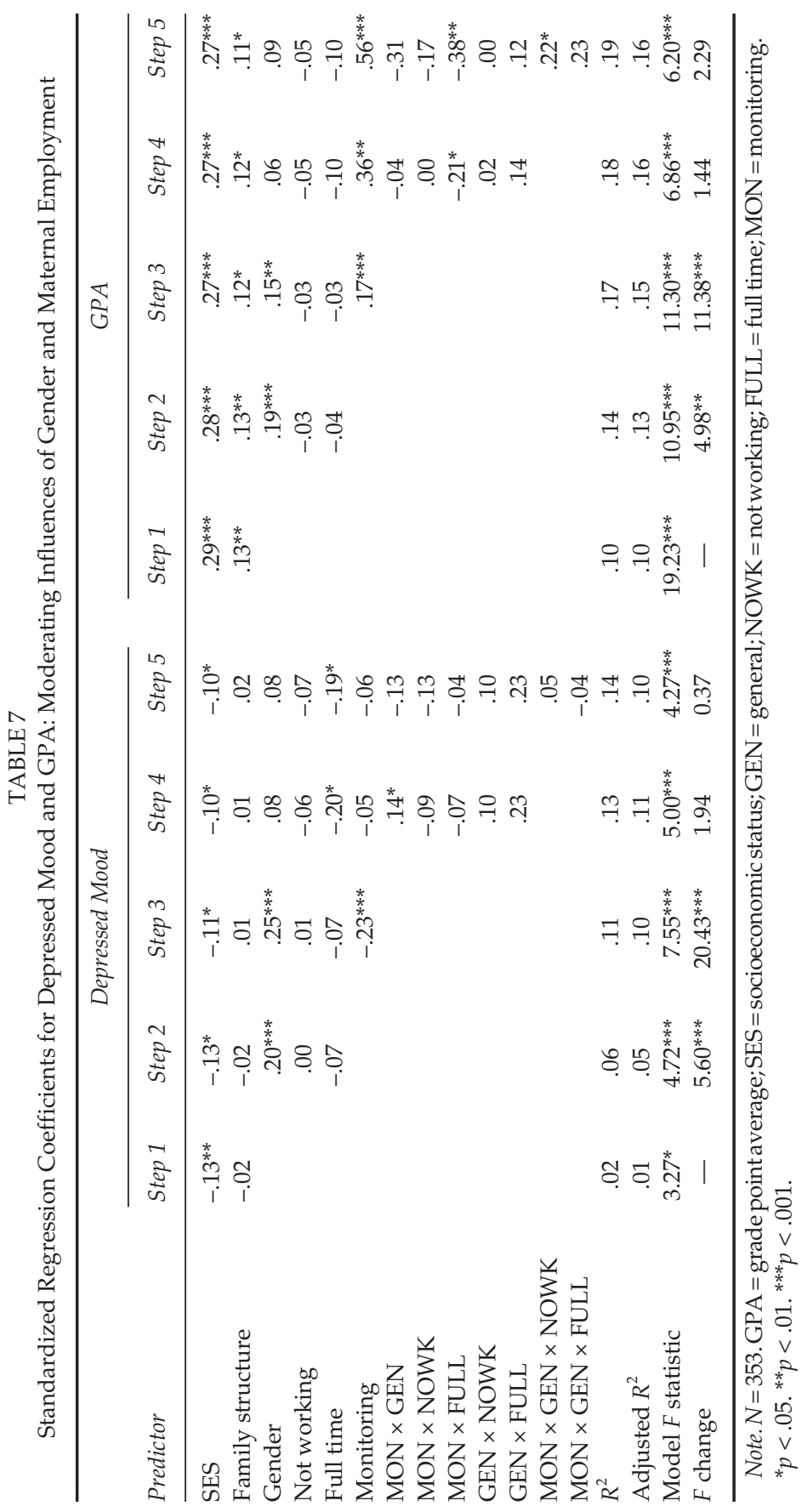


tween gender and full-time maternal employment was significant. Likewise, the three-way interactions as a set did not significantly increase the $R^{2}$, despite the significant interaction between monitoring, gender, and the dummy variable for not working (Model 5). The full model accounted for $16 \%$ of the variance in GPA.

In sum, these results indicate that higher levels of monitoring are associated with lower delinquency and sexual activity and that these relations are moderated by gender and maternal employment. Specifically, monitoring had a negative association with both behaviors among boys and girls whose mothers worked full time, among boys whose mothers worked part time, and among girls whose mothers did not work outside the home. Also, monitoring was positively related to GPA and negatively related to depression, but these relations did not appear to be moderated by gender and maternal employment status.

\section{DISCUSSION}

These results provide additional evidence that parental monitoring is related to adolescent psychosocial adjustment. The bivariate correlations demonstrate a moderate-to-strong association between parental monitoring and all indexes of adolescent adjustment, with the exception of boys' depression. Moreover, the addition of parental monitoring in each of the hierarchical regressions was significant, indicating that, when all adolescents are combined, parental monitoring had a significant main effect on adolescent outcomes. This is consistent with previous research that has found higher levels of parental monitoring to be associated with lower levels of antisocial or delinquent behavior (Reid \& Patterson, 1989; Sampson \& Laub, 1994; Snyder et al., 1986), greater academic achievement (Crouter et al., 1990; Dornbusch et al., 1987), less depressed mood (Barber et al., 1994), and lower levels of sexual behavior (Crockett \& Bingham, 1994; Hogan \& Kitagawa, 1985).

However, we also found evidence that some of the relations between parental monitoring and adolescent outcomes were moderated by gender and grade level, gender and maternal employment, or both. Evidence of moderating effects was found for the two problem behaviors: delinquency and sexual activity. Turning first to delinquency, a significant three-way interaction demonstrated that the relation between monitoring and adolescent delinquency increased with grade level among boys, but decreased with grade level among girls. The results for boys are largely consistent with Snyder et al. (1986), who found that monitoring was significantly related to association with deviant peers for 7 th- and 10th-grade boys, but 
not 4th-grade boys, indicating that monitoring has a stronger effect on older adolescents than on preadolescents. The finding that parental monitoring appears to be particularly important for younger girls accords with results reported by Galambos and Maggs (1991) and Steinberg (1986) who found that the relation between adult supervision and susceptibility to peer influence (Steinberg, 1986), problem behavior, and contact with deviant peers (Galambos \& Maggs, 1991) was actually stronger for young female adolescents than for young male adolescents (i.e., 6th grade for Galambos \& Maggs, 1991; and 6th-8th grade for Steinberg, 1986). Thus, in the arena of antisocial behavior, parental monitoring appears to be especially effective for younger girls and for older boys.

The significant Gender $\times$ Grade $\times$ Monitoring interaction found for adolescent delinquency may reflect gender differences in the timing of puberty. Girls mature faster than boys, and more advanced physical development may be related to an increased probability of associating with older peers. In turn, association with older peers may be related to a greater likelihood of engaging in problem behaviors. In a longitudinal study, Magnusson, Stattin, and Allen (1985) reported that among female adolescents, early maturing girls were more likely to be truant from school, use alcohol and drugs, and engage in delinquent behaviors than later maturing girls. Moreover, association with older peers was found to mediate the relation between maturational timing and problem behavior (Magnusson et al., 1985). However, differences between pubertal status groups diminished during later adolescence (Magnusson et al., 1985). Thus, it is possible that parental monitoring may be a more effective deterrent against problem behavior and school failure among younger female adolescents. Because male adolescents mature later than female adolescents, effective parental monitoring may not be as important in the junior high school years, but may increase in importance as boys enter puberty.

Although these results are in line with the general hypothesis that the effects of monitoring would vary by person characteristics, they do not support our specific hypothesis that the relation between monitoring and adjustment would show a curvilinear age pattern; in other words, that the relation between monitoring and adjustment would be stronger during the early high school years (i.e., 9th and 10th grade) than at younger or older ages. Such a curvilinear pattern has been reported in prior research by Small (1995) and Weintraub and Gold (1991). One possible reason for the divergent results is that neither of those studies examined the joint moderating influences of age and gender. It is unclear whether the curvilinear age patterns they report in the strength of the relation between monitoring and delinquency would have been found for both boys and girls. Alternatively, it is possible that this study lacked the statistical power 
to detect moderating effects involving a quadratic term. Interaction effects are difficult to uncover in general (e.g., McClelland \& Judd, 1993), and those involving polynomial terms require even more statistical power (Cohen \& Cohen, 1983). Thus, large sample sizes may be needed to fully investigate the possibility of complex moderating effects. As a point of comparison, the Weintraub and Gold (1991) study used the National Survey of Youth; a sample over three times as large as the one used in this study.

We also predicted that maternal employment would moderate the association between parental monitoring and adolescent adjustment. Such effects were found for delinquency and sexual activity. Based on the notion that careful monitoring might be especially important for adolescents whose mothers work full time and hence cannot supervise them directly, we expected parental monitoring to be more strongly associated with adjustment among adolescents whose mothers worked full time. This hypothesis received partial support. Specifically, we did find that for both boys and girls, higher levels of parental monitoring were associated with lower levels of delinquent behavior and lower levels of sexual activity among adolescents whose mothers worked full time.

However, the presence of significant Monitoring $\times$ Gender $\times$ Maternal Employment interactions found for adolescent delinquency and sexual activity indicates that the story may be somewhat more complex. For example, parental monitoring was significantly related to delinquency and sexual activity among girls whose mothers were not working, but not among girls whose mothers worked part time; the opposite pattern was found for boys. These results suggest that part-time maternal employment may also constitute a "risk" environment, but only for boys. Specifically, more effective monitoring may compensate for the lower level of direct supervision and attention experienced by boys whose mothers work part time. This is largely consistent with results from Crouter et al. (1990) who concluded that "less well-monitored boys in dual [earner] contexts look ... most problematic" (Crouter et al., 1990, p. 65). In contrast, part-time employment among mothers of female adolescents may actually be beneficial.

The premise that maternal employment may have different costs and benefits for boys versus girls can also be found in the literature on the main effects of maternal employment. In general, maternal employment has not been invariably related to poorer adjustment in children and adolescents (see Orthner, 1990, for a review). However, when effects have been found, they are usually moderated by gender. Specifically, maternal employment seems to be related to better adjustment for girls and poorer adjustment for boys (Montemayor, 1984; see also Montemayor \& Clayton, 1983; Orthner, 
1990, for reviews). Thus, overall, maternal employment may have benefits for girls that compensate for the lack of direct supervision.

However, it should be noted that we did not find a significant three-way interaction between gender, maternal employment, and monitoring for adolescent GPA. Likewise Crouter et al. (1990) also failed to find a significant three-way interaction between monitoring, gender, and maternal employment for academic achievement, although, similar to this study, they did find significant three-way interactions for their measures of problem behavior. The failure to find joint moderating influences of gender and maternal employment on the relation between monitoring and GPA may reflect issues of sample size and statistical power. For example, in this study, when measures of social class, gender, and maternal employment were controlled for, parental monitoring explained only $2 \%$ of the additional variance in adolescent GPA. If the overall relation between monitoring and adolescent GPA is weak, then it is unlikely that statistically significant interactions, particularly three-way interactions, could be found with this sample size. What is needed are larger studies, studies that examine family processes that are more strongly related to academic achievement, or both.

Finally, this study indicates that higher levels of monitoring are also related to lower levels of adolescent internalizing behaviors. This is consistent with results from Barber et al. (1994) who found that higher levels of behavioral control were related to lower levels of internalizing behaviors. Results from the hierarchical regression analyses suggest that the relation between monitoring and depressed mood is relatively robust across gender, grade, and maternal employment groups. However, it is also true that the two-way interaction between gender and monitoring was significant for adolescent depressed mood in both sets of regression analyses, and that the main effect of monitoring became nonsignificant when this interaction was included. In both the regressions (and the bivariate correlations), it appeared that the relation between monitoring and depression pertained mainly to girls. Nevertheless, the addition of the two-way interactions as a set did not account for a significant increase in variance in depressed mood in either of the two hierarchical regressions; thus, the significant interaction between gender and monitoring for adolescent depressed mood should be considered a preliminary finding. Future research should continue to explore potential gender differences in the relation between family processes and adolescent internalizing behaviors, and the causes of these gender differences. For example, Jacobson and Rowe (1999) found that the correlation between family warmth and adolescent depressed mood was stronger among girls than boys. Moreover, among girls, a large proportion of the covariation between warmth and depressed mood was due to common genetic factors. In contrast, common environmental factors explained 
most of the covariation among boys. This suggests that both the strength of the relation between family processes and depressed mood and the sources of this relation may be different for boys and girls.

These findings should be considered with several caveats in mind. First, cross-sectional studies such as this one cannot determine the causal relations among variables. Thus, although the conceptual model proposed here suggests that inefficient parental monitoring leads to poorer adolescent adjustment, it is equally possible that more problematic adolescents are more difficult to monitor effectively. Alternatively, parents who are unable to effectively monitor their children may have other problems or characteristics that are also related (through either genetic avenues, environmental avenues, or both) to higher levels of problem behavior in their children. Although the issue of causal sequence cannot be addressed here, it is important to note that experimental designs employed by Patterson and colleagues (e.g., Patterson, 1988) provide strong evidence that parenting practices, including monitoring and supervision, do affect later child and adolescent outcomes.

Second, all participants came from a single rural school district; hence, results may not generalize to urban or suburban adolescents. In addition, the active consent procedure employed resulted in a response rate of just over $40 \%$, making it likely that the adolescents who participated were better adjusted than those who did not, as is typical in studies that require voluntary participation (Beck, Collins, Overholser, \& Terry, 1984; Weinberger, Tublin, Ford, \& Feldman, 1990). Despite these considerations, our results largely accord with those of prior studies with different adolescent populations. The convergence between these findings and those of other investigators suggests that the relation of parental monitoring to adolescent adjustment is both pervasive and robust.

In conclusion, this study provides additional evidence for the importance of parental monitoring for adjustment across the junior high and high school years. In some cases, the strength of these associations was moderated by gender, grade, and maternal employment. Thus, this study also supports the usefulness of the ecological framework as a model for understanding adolescent development.

\section{ACKNOWLEDGMENTS}

This research was made possible by grants from the College of Health and Human Development and the Center for the Study of Child and Adolescent Development at Pennsylvania State University to Lisa J. Crockett and Patricia B. Koch. The results presented were part of Kristen C. Jacobson's mas- 
ters thesis in the Department of Human Development and Family Studies at Pennsylvania State University. Parts of this article were presented at the 1994 biennial meeting of the Society for Research on Adolescence in San Diego, CA.

We thank the students and participating school district for taking part in this study. We also thank Donna Ballock for her technical support.

\section{REFERENCES}

Aiken, L. S., \& West, S. G. (1991). Multiple regression: Testing and interpreting interactions. Newbury Park, CA: Sage.

Armistead, L., Wierson, M., \& Forehand, R. (1990). Adolescents and maternal employment: Is it harmful for a young adolescent to have an employed mother? Journal of Early Adolescence, 10, 260-278.

Barber, B. K., Olsen, E., \& Shagle, S. C. (1994). Associations between parental psychological and behavioral control and youth internalized and externalized behaviors. Child Development, 65, 1120-1136.

Beck, S., Collins, L., Overholser, J., \& Terry, K. (1984). A comparison of children who receive and who do not receive permission to participate in research. Journal of Abnormal Child Psychology, 12, 573-580.

Berndt, T. J. (1979). Developmental changes in conformity to peers and parents. Developmental Psychology, 15, 608-616.

Bronfenbrenner, U. (1979). The ecology of human development: Experiments by nature and design. Cambridge, MA: Harvard University Press.

Bronfenbrenner, U. (1986). Ecology of the family as a context for human development: Research perspectives. Developmental Psychology, 22, 723-742.

Bronfenbrenner, U. (1988). Interacting systems in human development. Research paradigms: Present and future. In N. Bolger, A. Caspi, G. Downey, \& M. Moorehouse (Eds.), Persons in context: Developmental processes (pp. 25-49). New York: Cambridge University Press.

Bronfenbrenner, U., \& Crouter, A. C. (1983). The evolution of environmental models in developmental research. In W. Kessen (Ed.), Handbook of child psychology: History, theories, and methods (Vol. 1, pp. 357-414). New York: Wiley.

Brown, B. B. (1990). Peer groups and peer cultures. In S. S. Feldman \& G. R. Elliott (Eds.), At the threshold: The developing adolescent (pp. 171-196). Cambridge, MA: Harvard University Press.

Brown, B. B., Mounts, N., Lamborn, S. D., \& Steinberg, L. (1993). Parenting practices and peer group affiliation in adolescence. Child Development, 64, 467-482.

Cohen, J., \& Cohen, P. (1983). Applied multiple regression/correlation analysis for the behavioral sciences (2nd ed.). Hillsdale, NJ: Lawrence Erlbaum Associates, Inc.

Crockett, L. J., \& Bingham, C. R. (1994). Family influences on girls' sexual experience and pregnancy risk. Unpublished manuscript, The Pennsylvania State University.

Crockett, L. J., Schulenberg, J. E., \& Petersen, A. C. (1987). Congruence between objective and self-report data in a sample of young adolescents. Journal of Adolescent Research, 2, 383-392.

Crouter, A. C., MacDermid, S. M., McHale, S. M., \& Perry-Jenkins, M. (1990). Parental monitoring and perceptions of children's school performance and conduct in dual- and single-earner families. Developmental Psychology, 26, 649-657.

Dishion, T. J., \& Loeber, R. (1985). Adolescent marijuana and alcohol use: The role of parents and peers revisited. American Journal of Drug and Alcohol Abuse, 11, 11-25. 
Donovan, J. E., \& Jessor, R. (1985). Structure of problem behavior in adolescence and young adulthood. Journal of Consulting \& Clinical Psychology, 53, 890-904.

Dornbusch, S., Ritter, P., Leiderman, P., Roberts, D., \& Fraleigh, M. (1987). The relation of parenting style to school performance. Child Development, 58, 1244-1257.

Ensminger, M. E. (1990). Sexual activity and problem behaviors among Black, urban adolescents. Child Development, 61, 2032-2046.

Foxcraft, D. R. (1994, February). Adolescent drinking behaviour: Family socialization influences develop with age. Paper presented at the meeting of the Society for Research on Adolescence, San Diego, CA.

Galambos, N. L., \& Maggs, J. L. (1991). Out-of-school care of young adolescents and self-reported behavior. Developmental Psychology, 27, 644-655.

Gold, M., \& Reimer, D. J. (1975). Changing patterns of delinquent behavior among Americans 13 through 16 years old: 1967-1972. Crime and Delinquency Literature, 7, 483-517.

Hogan, D. P., \& Kitagawa, E. M. (1985). The impact of social status, family structure, and neighborhood on the fertility of Black adolescents. American Journal of Sociology, 90, 825-855.

Huizinga, D., Esbensen, F., \& Weiher, A. W. (1991). Are there multiple pathways to delinquency? The Journal of Criminal Law and Criminology, 82, 83-118.

Jaccard, J., Turrisi, R., \& Wan, C. K. (1990). Interaction effects in multiple regression. Newbury Park, CA: Sage.

Jacobson, K. C., \& Rowe, D. C. (1999). Genetic and environmental influences on the relationships between family connectedness, school connectedness, and adolescent depressed mood: Sex differences. Developmental Psychology, 35, 926-939.

Kandel, D. B., \& Davies, M. (1982). Epidemiology of depressive mood in adolescents. Archives of General Psychiatry, 39, 1205-1212.

Larson, R., \& Richards, M. H. (1991). Daily companionship in late childhood and early adolescence: Changing developmental contexts. Child Development, 62, 284-300.

Linver, M. R., \& Silverberg, S. B. (1995). Parenting as a multidimensional construct: Differential prediction of adolescents' sense of self and engagement in problem behavior. Journal of Adolescent Medicine and Health, 8, 29-40.

Magnusson, D., Stattin, H., \& Allen, V. L. (1985). Biological maturation and social development: A longitudinal study of some adjustment processes from mid-adolescence to adulthood. Journal of Youth and Adolescence, 14, 267-283.

McClelland, G. H., \& Judd, C. M. (1993). Statistical difficulties of detecting interaction and moderator effects. Psychological Bulletin, 114, 376-390.

Menard, S., \& Elliott, D. S. (1990). Self-reported offending, maturational reform, and the Easterlin hypothesis. Journal of Quantitative Criminology, 6, 237-267.

Montemayor, R. (1984). Maternal employment and adolescents' relations with parents, siblings, and peers. Journal of Youth and Adolescence, 13, 543-557.

Montemayor, R., \& Clayton, M. D. (1983). Maternal employment and adolescent development. Theory Into Practice, 22, 112-118.

Orthner, D. K. (1990). Parental work and early adolescence: Issues for research and practice. Journal of Early Adolescence, 10, 246-259.

Patterson, G. (1988). Family process: Loops, levels, and linkages. In N. Bolger, A. Caspi, G. Downey, \& M. Moorehouse (Eds.), Persons in context: Developmental processes (pp. 114-151). New York: Cambridge University Press.

Patterson, G. R., \& Stouthamer-Loeber, M. (1984). The correlation of family management practices and delinquency. Child Development, 55, 1299-1307.

Reid, J. B., \& Patterson, G. R. (1989). The development of antisocial behaviour patterns in childhood and adolescence. European Journal of Personality, 3, 107-119. 
Sampson, R. J., \& Laub, J. H. (1994). Urban poverty and the family context of delinquency: A new look at structure and process in a classic study. Child Development, 65, 523-540.

Small, S. A. (1995). Enhancing contexts of adolescent development: The role of community-based action research. In L. J. Crockett \& A. C. Crouter (Eds.), Pathways through adolescence (pp. 211-233). Hillsdale, NJ: Lawrence Erlbaum Associates, Inc.

Snyder, J., Dishion, T. J., \& Patterson, G. R. (1986). Determinants and consequences of associating with deviant peers during preadolescence and adolescence. Journal of Early Adolescence, 6, 29-43.

Steinberg, L. (1986). Latchkey children and susceptibility to peer pressure: An ecological analysis. Developmental Psychology, 22, 433-439.

Steinberg, L. (1990). Autonomy, conflict, and harmony in the family relationship. In S. S. Feldman \& G. R. Elliott (Eds.), At the threshold: The developing adolescent (pp. 255-276). Cambridge, MA: Harvard University Press.

Steinberg, L., Elmen, J. D., \& Mounts, N. S. (1989). Authoritative parenting, psychosocial maturity, and academic success among adolescents. Child Development, 60, 1424-1436.

Steinberg, L., Mounts, N. S., Lamborn, S. D., \& Dornbusch, S. (1991). Authoritative parenting and adolescent adjustment across varied ecological niches. Journal of Research on Adolescence, 1, 19-36.

Stevens, G., \& Hoisington, E. (1987). Occupational prestige and the 1980 U.S. labor force. Social Science Research, 16, 74-105.

Swisher, J., Shute, R. E., \& Bibeau, D. (1984). Assessing drug and alcohol abuse: An instrument for planning and evaluation. Measurement and Evaluation in Counseling and Development, 17, 91-97.

Weinberger, D. A., Tublin, S. K., Ford, M. E., \& Feldman, S. S. (1990). Social-emotional adjustment and selective attrition in family. Child Development, 61, 1374-1386.

Weintraub, K. J., \& Gold, M. (1991). Monitoring and delinquency. Criminal Behaviour and Mental Health, 1, 268-281. 